\title{
Minimizing the adverse public health effects of cannabis legalization
}

\author{
Wayne Hall PhD
}

- Cite as: CMAJ 2018 September 4;190:E1031-2. doi: 10.1503/cmaj.181035

See related article at www.cmajopen.ca/content/6/3/E339

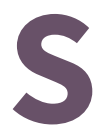

ince 1961, cannabis has been classified along with the opiates and cocaine as a drug that presents such a serious danger to health that its use by adults should be prohibited, except for medical or scientific purposes. ${ }^{1}$ Critics of cannabis prohibition have long claimed, however, that cannabis is much less harmful than the legal substances alcohol and tobacco, and that its health risks have been exaggerated. ${ }^{2}$ Until recently, arguments that the social and economic costs of criminalizing cannabis use outweigh its adverse health effects, that cannabis should be legalized for adult use, and that cannabis products should be taxed and regulated like alcohol, have gained very little political support. ${ }^{3}$ Since 2012 , however, the citizens of eight states in the United States have approved referenda to legalize the production, sale and adult use of cannabis. ${ }^{3}$ The Uruguayan government became the first nation to legalize cannabis in 2013, and Canada is preparing to do so in October 2018. Policy-makers in countries that legalize cannabis use must decide what to tell the community about its health risks.

In a linked study published in CMAJ Open, Memedovich and colleagues summarize the findings of 68 systematic reviews of research on the adverse health effects of cannabis. ${ }^{4}$ They found associations between cannabis use and increased risks of the following: mental health disorders, such as psychosis, mania, anxiety and suicide; changes in brain structure and function; poorer cognitive outcomes; poor pregnancy outcomes; and testicular cancer. They reported inconclusive evidence for 20 other mental health outcomes, other types of cancers and all causes of mortality.

The study's authors judged the reviews to be of low to moderate quality, but argued that there was enough evidence to justify public health measures aimed at minimizing risks from cannabis use. These included informing the public about the risks of mental disorders and brain changes, and encouraging medical practitioners to counsel patients regarding cannabis use. Public health messaging, they suggested, should target groups at higher risk of adverse outcomes, such as adolescents, people with mental disorders and pregnant women.

A dependence syndrome is the most common consequence of regular cannabis use. ${ }^{5}$ It is also the pattern of use most strongly

\section{KEY POINTS}

- Accumulated evidence indicates that cannabis use increases the risk of some mental disorders, cognitive difficulties, poor pregnancy outcomes and testicular cancer, and may be associated with development of other cancers.

- A dependence syndrome is the most common consequence of regular cannabis use.

- Governments that legalize cannabis should ensure that the public is well informed about its potential harms and how to avoid associated health and social problems.

- Canada has a unique opportunity to ensure that its regulation of a legal cannabis industry protects the health of people more effectively than regulatory models that have been implemented to date in other jurisdictions.

associated with psychosis, poor mental health, cognitive impairment and school failure. ${ }^{5,6}$ The health problems reported by people with cannabis dependence are less serious than those reported by people with alcohol dependence, ${ }^{7}$ but an inability to control one's cannabis use can be a major problem for someone who may not want to spend their days intoxicated and struggling to perform everyday social roles. Increased numbers of people are seeking treatment for cannabis dependence, including in the Netherlands, where cannabis use was decriminalized more than 40 years ago. ${ }^{8}$

The commonly cited risk - that $9 \%$ of lifetime users develop cannabis dependence - is probably an underestimate. It comes from population surveys conducted in the early 1990s when most cannabis users did not use frequently enough to put themselves at risk of dependence. ${ }^{9}$ The risk of developing cannabis dependence is likely higher now, and legalization may make cannabis cheaper and more readily available, and the tetrahydrocannabinol content of cannabis is higher now than it was in the early 1990s. ${ }^{2,10}$ Cannabis users will need credible advice on how to minimize the risks of dependence, and the health and psychosocial problems associated with it, such as that outlined in a recent guideline by Fischer and colleagues. ${ }^{11}$ 
Governments also have to decide how to regulate the production, processing and sale of cannabis products. Most of the US states that have legalized cannabis have adopted a model like that used to regulate alcohol. ${ }^{7}$ However, recent liberalization of alcohol regulation - as an ordinary commodity rather than as an intoxicating and addictive drug - makes it doubtful that this approach will minimize the adverse public health effects of cannabis use. Many jurisdictions impose few restrictions on where and when alcohol can be sold, and alcohol taxes have often not increased with inflation, effectively lowering its unit price. The alcohol industry has frequently been allowed to promote the heavy use of its products to maximize their profits, and it has effectively opposed public health regulations that would reduce access and increase taxes to reduce heavy alcohol use. ${ }^{12}$

A legal for-profit cannabis industry regulated in this way can be expected to behave like the alcohol industry. Its best customers will be daily users, many of whom may be problem users. ${ }^{9}$ Such an industry will therefore have an interest in maximizing the number of daily users and in recruiting new users to replace those who quit. It is likely that the industry will lobby to reduce taxes on cannabis, market more potent cannabis products (e.g., extracts) and minimize restrictions on the availability, advertising and use of cannabis. Marketing efforts will likely exaggerate the medical and "wellness" benefits of using cannabis as well as contest evidence that cannabis use can be harmful, including evidence on the harms associated with the riskiest pattern of cannabis use: daily use that begins in adolescence and continues throughout young adulthood.

Along with legalization, Canada will need to enact regulations and public health campaigns to minimize the harms of daily use, especially among young people, pregnant women and people with mental disorders. Canada has a unique opportunity to ensure that its regulation of a legal cannabis industry protects the public health more effectively than the regulatory models that have been implemented to date in the US.

\section{References}

1. Hall WD. The future of the international drug control system and national drug prohibitions. Addiction 2018;113:1210-23.

2. Rolles S, Murkin G. How to regulate cannabis: a practical guide. 2nd ed. Bristol (UK): Transform Drug Policy Foundation; 2014. Available: www.tdpf. org.uk/resources/publications/how-regulate-cannabis-practical-guide (accessed 2018 Aug. 2).

3. Kilmer B, MacCoun R. How medical marijuana smoothed the transition to marijuana legalization in the United States. Annu Rev Law Soc Sci 2017; 13:181-202.

4. Memedovich KA, Dowsett LE, Spackman E, et al. The adverse health effects and harms related to marijuana use: an overview review. CMAJ Open 2018; 6:E339-46.

5. Hall WD, Renström M, Poznyak V, editors. The health and social effects of nonmedical cannabis use. Geneva: World Health Organization; 2016. Available: www.who.int/substance_abuse/publications/msb_cannabis_report.pdf (accessed 2016 May 20).

6. Silins E, Horwood L, Patton G, et al. Young adult sequelae of adolescent cannabis use: an integrative analysis. Lancet Psychiatry 2014;1:286-93.

7. Hall WD. Alcohol and cannabis: comparing their adverse health effects and regulatory regimes. Int J Drug Policy 2017;42:57-62.

8. Drug treatment overview for Netherlands. Lisbon: European Monitoring Centre for Drugs and Drug Addiction; 2013. Available: www.webcitation.org/6S4yjPY59 (accessed 2014 July 23).

9. Caulkins J. The real dangers of marijuana. National Affairs 2016;26:21-4.

10. Hall WD, Lynskey M. Evaluating the public health impacts of legalizing recreational cannabis use in the USA. Addiction 2016;111:1764-73.

11. Fischer B, Russell C, Sabioni P, et al. Lower-risk cannabis use guidelines: a comprehensive update of evidence and recommendations. Am J Public Health 2017;107:e1-12.

12. Babor T, Caetano R, Casswell S, et al. Alcohol: no ordinary commodity: research and public policy. 2nd ed. Oxford (UK): Oxford University Press; 2010.

\section{Competing interests: None declared.}

This article was solicited and has not been peer reviewed.

Affiliations: Centre for Youth Substance Abuse Research, The University of Queensland, Queensland, Australia; National Addiction Centre, King's College London, London, UK

Correspondence to: Wayne Hall,w.hall@uq.edu.au 